\title{
Gender Equality and Institutions as the Driving Force of Football Performance: Women vs Men
}

\author{
By Jakub Harman*
}

\begin{abstract}
Gender equality should be a necessity in every developed economy of the world. Despite this assumption, this is not the case. The field of sports is no exception. This study addresses the relationship between gender equality, institutions and football performance of national teams. Correlation and regression analysis is used to determine the relationship between variables. The results suggest that higher gender equality leads to better performance for footballers on the fields. Countries with higher gender equality perform better (more FIFA points). The economic condition of the country has a similar effect on performance. Estimates have shown a statistically significant positive relationship between economic prosperity and performance on the pitch. Climate and age of players do not affect the performance of national teams. Institutional factors significantly affect players' performance. Members of the European Union perform significantly higher than those that are not in the EU. As well as countries in which there was no communist regime in the past ${ }^{l}$.
\end{abstract}

Keywords: gender inequality index, FIFA ranking, men, women, institutions

\section{Introduction}

Football is clearly a global phenomenon in the field of sports. Every weekend, millions of fans watch football matches in the best football competitions in the world (England, Spain, Germany, Italy and France). Quality football has not escaped the sight of researchers and the experts. Many research articles have focused on quantifying football success (Hofmann et al. 2006) or the economic and financial performance of clubs (Pinnuck and Potter 2006, Cintia et al. 2015). Some focus on motivation of football spectators to watch matches (Correia and Esteves 2007). However, our contribution in this respect is slightly out of line with current trends. The paper focuses on the quantification of the relationship between the football performance of national teams and gender equality in a given country expressed by the Gender Equality Index. It also focuses on institutional factors affecting the performance of representations. At the same time, we focus the research on the performance of both sexes. According to our knowledge, there are few studies that address this relationship, which is why this area of our research is interesting. One of the motivators for solving this problem is the current trend of promoting gender equality in remuneration, opportunities, or other spheres of the national economy. The second motivator is the fact that the women's sports industry has been gaining in importance in recent years. The number of television

\footnotetext{
*PhD Candidate, University of Economics in Bratislava, Slovak Republic.

${ }^{1}$ The paper is a part of the research project VEGA no. 1/0037/20 "New challenges and solutions for employment growth in changing socio-economic conditions".
} 
broadcasts that cover women's football is increasing significantly. This inextricably leads to an increase in the economic importance of the sector.

\section{Literature Review}

A study by Hoffman et al. (2002) is considered a pioneering study of football performance and socio-economic indicators. Their results show that economic, demographic, cultural and climatic factors are important. The authors have revealed inverted U-shaped relationships in the case of the country's climate and economic prosperity. Similarly, population and Latin origin play an important role.

In the relationship between institutional security and football performance, Houston and Wilson (2002) focused on 179 countries and their membership in FIFA measured by the number of years in the organization. The results of their study suggest that membership in FIFA has a positive effect on the performance of individual teams. Performance is also positively correlated with the country's wealth but diminishing economies of scale are emerging.

The study by Hoffmann et al. (2006) is one of the most important in the field. The authors use data from 88 countries for 2002 for women's international football performance and compare it with the performance of their male colleagues. They also include variables of political and gender inequality, namely the income ratio of women and men. Their findings showed that economic and demographic factors have the same effect on the game of men and women, while the effects of political and cultural factors differ. The findings of their study were later criticized.

Macmillan and Smith (2007) identified statistical discrepancies in the pioneering work of Hoffman et al. (2002), including selection bias and number of outliers. The authors therefore added more than 100 observations to the sample and estimated the data as cross-sectional for 2,000. Their results confirmed doubts about the results of Hoffman et al. (2002) whether the country is of Latin origin or not. The authors also identified several new variables affecting football performance.

Leeds and Markova Leeds (2009) argue that football success can be measured in two ways: by measuring a national team's success over time (dynamic approach) or by the number of FIFA points a nation has at a particular point (static approach). The authors concluded that the stronger the country's domestic league, the stronger the national team. Investing in the domestic league is therefore one of the ways to improve the performance of the national team.

Berlinschi et al. (2013) made an estimate for 202 countries for 2010, taking into account FIFA points and FIFA assessments. The authors examine the impact of the migration of professional footballers on their countries of origin. They found that the migration of international football players is improving performance, especially in countries with lower quality domestic leagues.

Jacobs (2014) studies the determinants of women's international football performance. This study uses data from 2006 for 139 FIFA member countries. In the models, the authors check variables for economic factors, gender equality, talent, climate, as well as political and cultural factors. The author shows that 
dedicated management and training are key predictors of successful football countries.

\section{Methodology}

The paper deals with the relationship between the performance of football teams and gender equality measured by the Gender Inequality Index as well as other socio-economic or institutional factors. The data collected cover 51 countries (Europe, the Caucasus and Kazakhstan) for 2019. The data sources are from publicly available statistical databases of FIFA ${ }^{2}$, the World Bank ${ }^{3}$, TransferMarkt ${ }^{4}$ and the United Nations Development Program ${ }^{5}$. Table 1 provides a descriptive statistics of observed variables. Women have reached more points than men on average. The standard deviation is also higher for women, which means that the variation in team quality is higher for women than for men. About half of the countries are members of the European Union and a similar number had a communist regime in the past.

Table 1. Descriptive Statistics

\begin{tabular}{|l|c|c|c|c|c|}
\hline & Mean & Sd. Dev. & Min & Max & $\begin{array}{c}\text { Exp. } \\
\text { Effect }\end{array}$ \\
\hline Women & 1524.975 & 315.23 & 749 & 2088.72 & \\
\hline Men & 1413.532 & 211.347 & 940.3 & 1832.33 & \\
\hline GDPpc & 30016.645 & 24429.451 & 3115.861 & 107457.99 & + \\
\hline Temperature & 8.908 & 4.406 & -5.1 & 19.2 & $+/-$ \\
\hline EU & 0.529 & 0.504 & 0 & 1 & + \\
\hline Post_Communist & 0.471 & 0.504 & 0 & 1 & - \\
\hline Age (Male) & 26.806 & 0.81 & 25.2 & 28.4 & + \\
\hline Age (Female) & 24.291 & 1.599 & 20.643 & 27.667 & + \\
\hline GII & 0.143 & 0.083 & 0.025 & 0.331 & - \\
\hline
\end{tabular}

From a methodological point of view, the paper uses correlation and regression analysis. We estimate the linear function for football performances represented by the number of points in the FIFA ranking. In the case of the relationship, we estimate the equation in the form:

$$
\begin{gathered}
Y_{i}=\beta_{0}+\beta_{1} G I I_{i}+\beta_{2} \log _{-} G D P p c_{i}+\beta_{3} \text { Temperature }_{i}+\beta_{4} \text { Age }_{i}+\beta_{4} \text { Age }_{i}^{2} \\
+\varepsilon_{i} \text { (1) }
\end{gathered}
$$

\footnotetext{
${ }^{2}$ Available at: < https://www.fifa.com/fifa-world-ranking $>$.

${ }^{3}$ Available at: < https://data.worldbank.org/>.

${ }^{4}$ Available at: < www.transfermarkt.com>.

${ }^{5}$ Available at: < http://hdr.undp.org/en/content/gender-inequality-index-gii>.
} 
Where:

- $\mathrm{Y}_{\mathrm{i}}$ is the FIFA ranking of the men's and women's national teams in country i.

- $\mathrm{GII}_{\mathrm{i}}$ is the Gender Inequality Index in country $\mathrm{i}$.

- $\mathrm{GDPpc}_{\mathrm{i}}$ is the gross domestic product per capita in country $i$.

- Temperature $_{\mathrm{i}}$ is a variable that takes into account the climate and the outside temperature in country $i$.

- $\mathrm{Age}_{\mathrm{i}}$ is the average age of the national teams in country $i$.

- $\varepsilon_{\mathrm{i}}$ is an error term.

One of the goals of the paper is to quantify the institutional implications for the football performance of national teams. We estimate this relationship by the following equation:

$$
Y_{i}=\beta_{0}+\beta_{1} E U_{i}+\beta_{2} \text { Post_Communist }_{i}+\beta_{3} E U * \text { Post_Communist }_{i}+\varepsilon_{i}
$$

Where:

- $\mathrm{Y}_{\mathrm{i}}$ is the FIFA ranking of the men's and women's national teams in country i.

- $\mathrm{EU}_{\mathrm{i}}$ is a dummy variable expressing whether a country is in the European Union or not.

- Post_Communist $t_{i}$ is a dummy variable expressing whether there was a communist regime in the country in the past or not.

- EU*Post_Communist $t_{i}$ is an interaction variable that takes into account whether the country was communist and is currently part of the European Union.

- $\varepsilon_{\mathrm{i}}$ is an error term.

The Gender Inequality Index measures gender inequalities in three important aspects of human development - reproductive health, as measured by maternal mortality rates and adolescent birth rates; empowerment measured by the proportion of parliamentary seats occupied by women and the proportion of adult women and men aged 25 and over with at least some secondary education; and economic status, expressed as labor market participation and measured by the labor force participation rate of the female and male population aged 15 and over (UNDP). The higher the GII value, the greater the inequalities between women and men and the greater the loss to human development. The GII value ranges between 0 and 1 , with 0 being $0 \%$ inequality, which means that women are treated the same as men, and 1 is $100 \%$ inequality, which means that women are doing poorly compared to men. In the case of the impact of the index on football performance, we assume that gender equality will have a positive effect on the quality of their performance. This gives hypothesis 1 . 
H1: Gender equality has a positive effect on the football performance of national teams.

The economic situation of countries is captured using the variable GDPpc, which expresses the gross domestic product per capita in the country. We assume that higher income in the country will mean better infrastructure, better stadiums, better training facilities for players and higher quality coaches. For this reason, we assume that the relationship between performance and income will be positive.

$\mathrm{H} 2$ : Income per capita has a positive effect on the football performance of national teams.

The right "operating" temperature during a football match can have a significant effect on the performance on the field. The literature indicates that the true temperature is approximately 14 degrees Celsius (Hoffmann et al. 2006). Therefore, we use variable Temperature, which takes into account the average air temperature in the country. The variable is centered at 14 degrees Celsius, which means that its values represent a deviation from this value.

H3: The air temperature in the country affects the performance on the field.

We believe that the age of the players will have a significant impact on the performance of the team. With older age, very important football experience and wisdom are brought to the team. Combined with youthful predation, the experience of older players is an important aspect of national team performance. However, the assumption is that the performance of players decreases from a certain age, because they are no longer able to keep up with their younger colleagues. For this reason, the age squared is also incorporated into the function.

H4: Age has a positive effect on team performance.

Institutional factors play an important role and are among the most important factors influencing the sporting situation in the country. Institutional factors include, for example, sports infrastructure, the quality of stadiums, lawns, training facilities or the bureaucratic burden on players during transfers and many others. We assume, for example, that the bureaucratic burden on players is significantly lower in the event of a transfer within the European Union, which means that players from "weaker football leagues" can also get into the top leagues more easily than players from third countries. Similarly, we assume that countries that used to have a communist regime have infrastructure built at a lower level, and therefore the quality of their results will be lower.

H5: EU countries perform better than non-EU countries.

H6: Post-communist countries perform weaker than Western countries. 


\section{Results}

The aim of the paper is to identify the relationship between the football performance of national teams and gender equality and institutional factors in the country.

Figure 1. FIFA Points Density (Men)

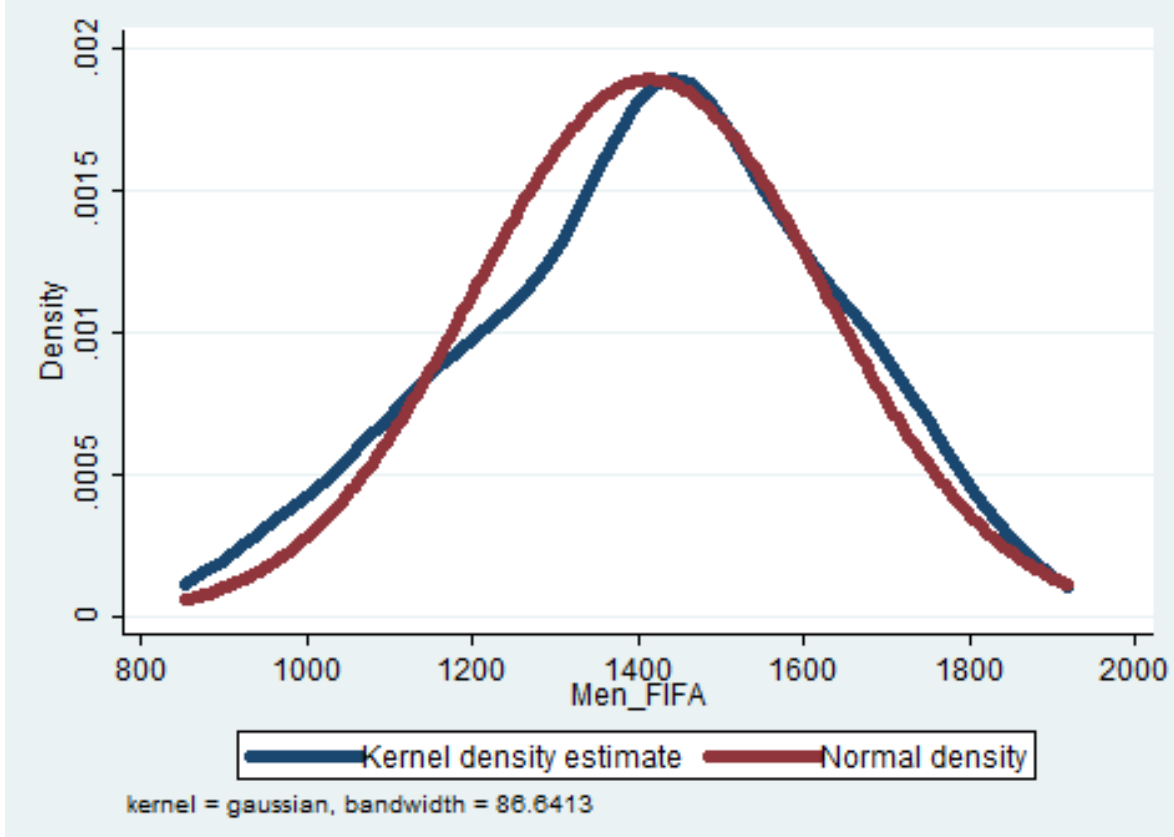

Source: FIFA, own calculations.

Figure 2. FIFA Points Density (Women)

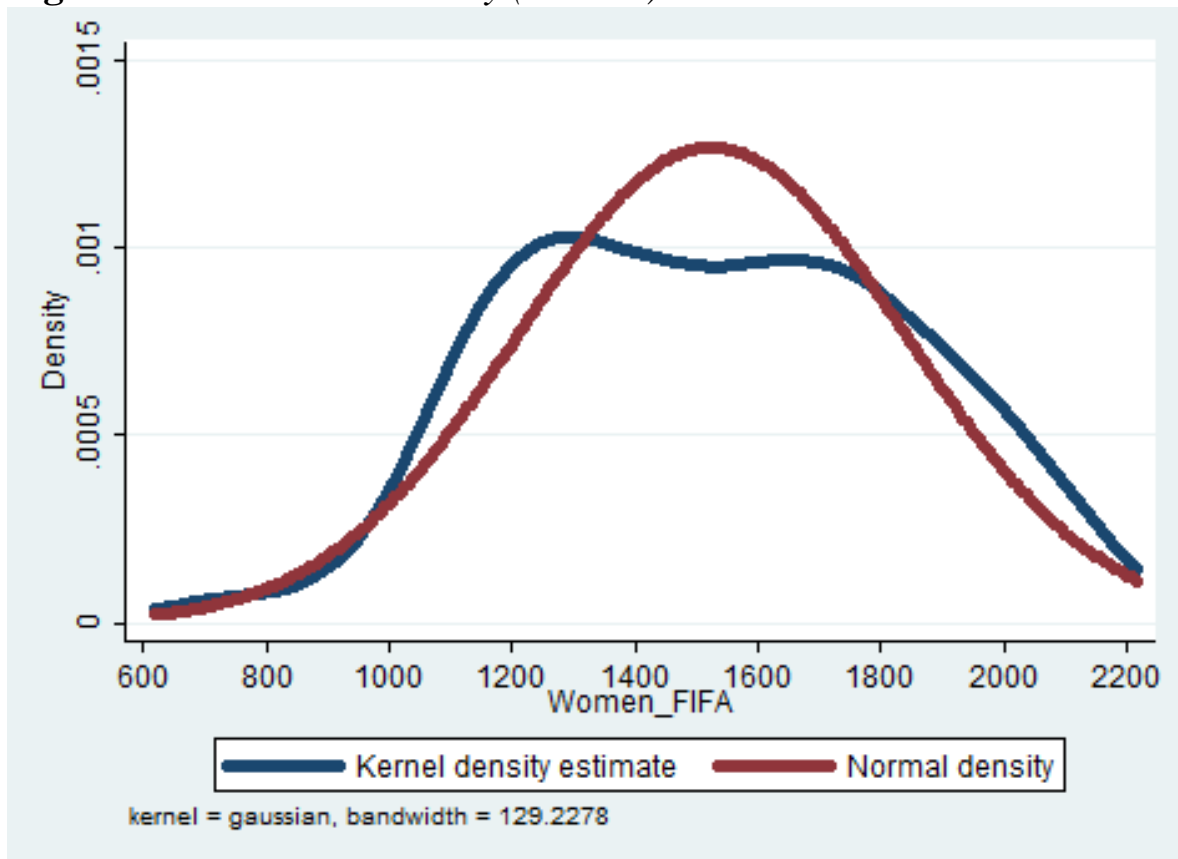

Source: FIFA, own calculations. 
Figures 1 and 2 provide an insight into the density distribution of FIFA points by gender. The distribution of men's points is very similar to the normal distribution. This indicates a high level of competition between the teams and only a few outliers who have a small/large deviation compared to the average. In the case of women, we see a slight bevel to the left. This means that there are several teams with a low number of points in the selection. These teams are therefore weaker than the rest of the selection. It also suggests greater variation in data and inequalities in the quality of women's football teams as opposed to men, where greater equality prevails.

Figure 3 shows the relationship between the FIFA points achieved by national teams by gender and the Gender Inequality Index. We assume that the relationship between these variables is negative. We know that higher index values mean higher gender inequality and, according to the graph, lead to lower FIFA points. Inequalities therefore negatively affect the quality of football players' performance for both sexes. This relationship is stronger for women than for men.

Figure 3. Scatter FIFA-GII

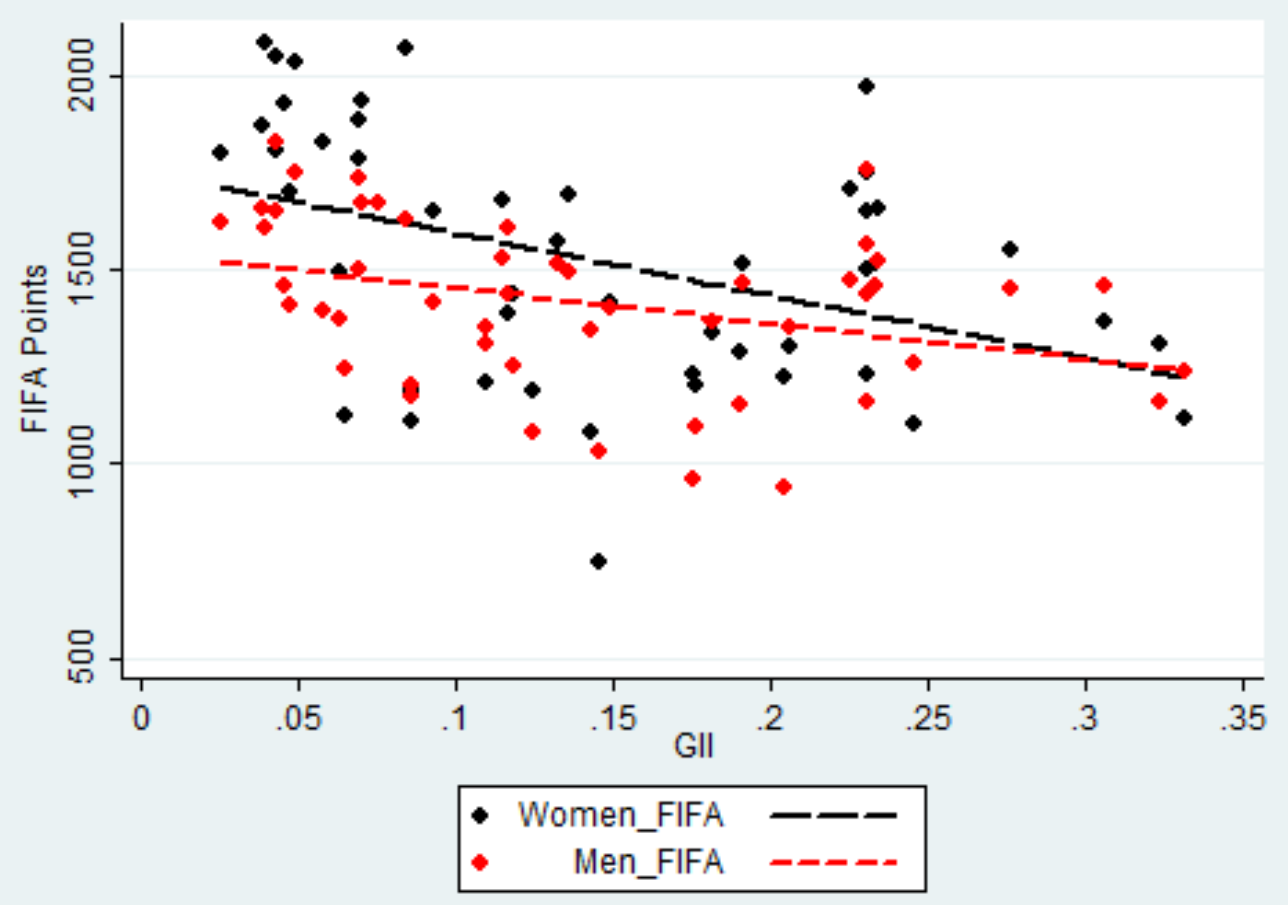

Source: FIFA, World Bank, own calculations.

Figure 4 provides an insight into the relationship between football performance and the country's economic prosperity in terms of gross domestic product per capita. We can see from the graph that the variables are positively correlated. Higher per capita income leads to better results. We assume that countries with a higher gross domestic product will have a better sports infrastructure (stadiums, training grounds, availability of sports grounds, etc.). Consequently, the results on the field are better than in the case of countries with worse economic conditions. The relationship is stronger for women. 
Figure 4. Scatter FIFA-GDP per Capita

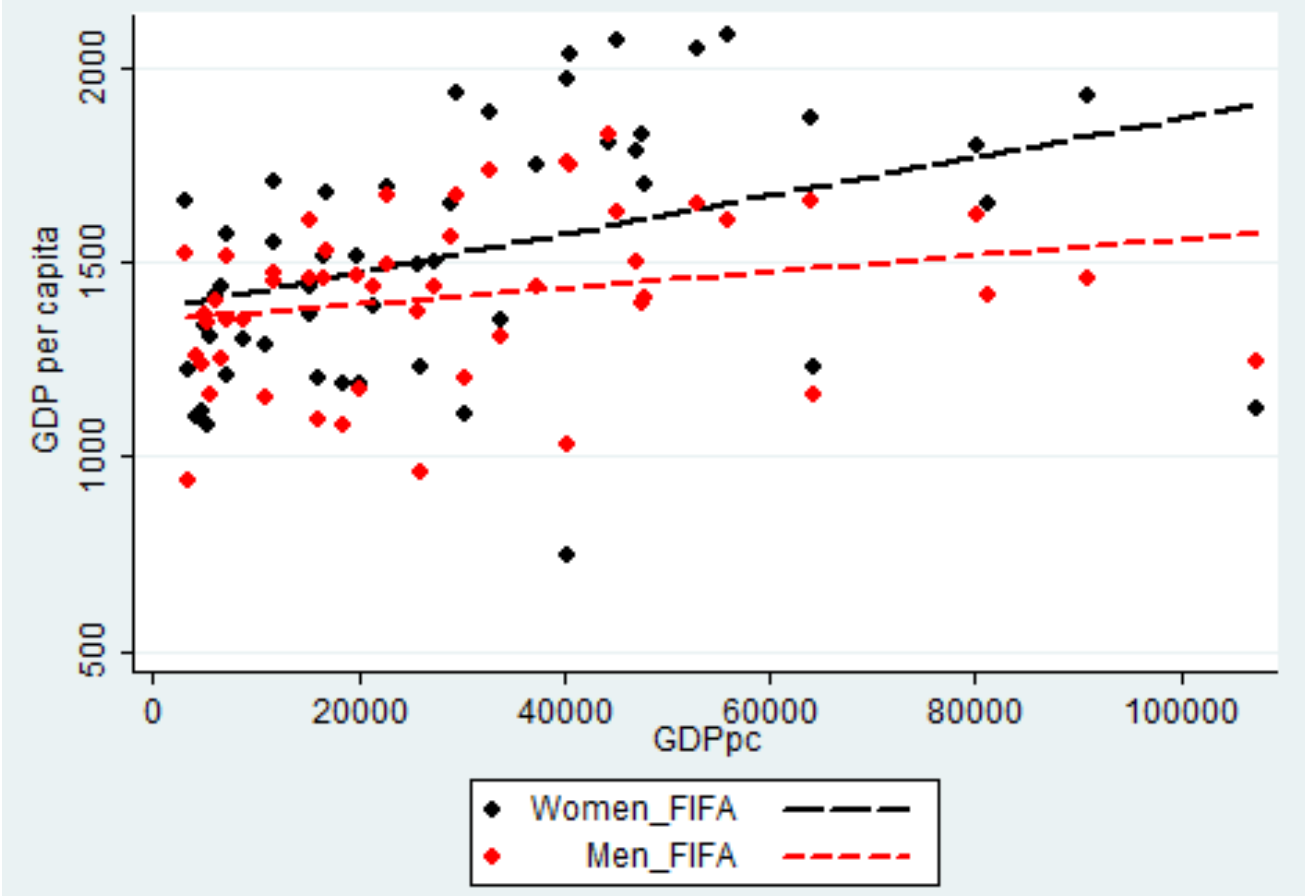

Source: FIFA, World Bank, own calculations.

Table 2 shows the individual correlation coefficients between the observed variables. The p-value is given in parentheses. The main interest is lines 3 and 4, which show the coefficients between gender inequality and per capita income. There is a negative statistically significant relationship between the gender inequality index and football performance, which supports our hypothesis. In the case of the economic situation in the country and football performance, there is a positive statistically significant correlation. Membership in the European Union also positively correlates with the results of national teams. In countries where the communist regime was in the past, the correlation is negative and statistically significant. 
Table 2. Correlation Matrix

\begin{tabular}{|c|c|c|c|c|c|c|c|c|c|c|}
\hline & (1) & (2) & (3) & (4) & (5) & (6) & (7) & (8) & (9) & (10) \\
\hline (1) Women & 1.000 & & & & & & & & & \\
\hline & & & & & & & & & & \\
\hline \multirow{2}{*}{ (2) Men } & $0.826 * * *$ & 1.000 & & & & & & & & \\
\hline & $(0.000)$ & & & & & & & & & \\
\hline \multirow[t]{2}{*}{ (3) GDPpc } & $0.463 * * *$ & $0.334 * *$ & 1.000 & & & & & & & \\
\hline & $(0.001)$ & $(0.017)$ & & & & & & & & \\
\hline \multirow[t]{2}{*}{ (4) GII } & -0.420 **** & $-0.358 * * *$ & $-0.594 * * *$ & 1.000 & & & & & & \\
\hline & $(0.002)$ & $(0.010)$ & $(0.000)$ & & & & & & & \\
\hline \multirow[t]{2}{*}{$\begin{array}{l}\text { (5) } \\
\text { Temperature }\end{array}$} & -0.212 & -0.022 & -0.091 & 0.043 & 1.000 & & & & & \\
\hline & $(0.135)$ & $(0.878)$ & $(0.527)$ & $(0.762)$ & & & & & & \\
\hline \multirow[t]{2}{*}{$\begin{array}{l}\text { (6) Age } \\
\text { (Male) }\end{array}$} & -0.088 & -0.015 & -0.046 & -0.099 & $\begin{array}{l}-0.167 \\
\end{array}$ & 1.000 & & & & \\
\hline & $(0.541)$ & $(0.919)$ & $(0.749)$ & $(0.487)$ & $(0.243)$ & & & & & \\
\hline \multirow[t]{2}{*}{$\begin{array}{l}\text { (7) Age } \\
\text { (Female) }\end{array}$} & $0.623^{* * * *}$ & $0.503^{* * * *}$ & $0.421^{* * *}$ & -0.179 & -0.217 & -0.027 & 1.000 & & & \\
\hline & $(0.000)$ & $(0.000)$ & $(0.002)$ & $(0.209)$ & $(0.126)$ & $(0.850)$ & & & & \\
\hline \multirow[t]{2}{*}{ (8) $\mathrm{EU}$} & $0.252^{*}$ & $0.244^{*}$ & $0.388^{* * * *}$ & $\begin{array}{c}- \\
0.473^{* *} \\
*\end{array}$ & 0.144 & -0.032 & 0.190 & 1.000 & & \\
\hline & $(0.075)$ & $(0.084)$ & $(0.005)$ & $(0.000)$ & $(0.312)$ & $(0.822)$ & $(0.182)$ & & & \\
\hline \multirow[t]{2}{*}{$\begin{array}{l}\text { (9) } \\
\text { Post_Comm }\end{array}$} & $-0.425 * * * *$ & $-0.348^{* * *}$ & $-0.806^{* * * *}$ & $\begin{array}{c}0.417^{* *} \\
*\end{array}$ & -0.197 & 0.062 & $-0.473^{*}$ & -0.134 & 1.000 & \\
\hline & $(0.002)$ & $(0.012)$ & $(0.000)$ & $\begin{array}{l}(0.002) \\
\end{array}$ & $(0.167)$ & $\begin{array}{l}(0.667) \\
\end{array}$ & $(0.000)$ & $(0.348)$ & & \\
\hline \multirow{2}{*}{$\begin{array}{l}(10) \\
\text { EU*Comm }\end{array}$} & -0.155 & -0.107 & -0.122 & 0.085 & -0.109 & -0.040 & -0.203 & $0.494^{* * * *}$ & $0.556^{* * * *}$ & 1.000 \\
\hline & $(0.278)$ & $(0.455)$ & $(0.395)$ & $(0.552)$ & $\begin{array}{l}(0.446) \\
\end{array}$ & $(0.783)$ & $\begin{array}{l}(0.154) \\
\end{array}$ & $(0.000)$ & $\begin{array}{l}(0.000) \\
\end{array}$ & \\
\hline
\end{tabular}

In Table 3 we find the core of the analysis, which is an estimate of the linear function. The table shows 4 models, 2 for women and 2 for men. Model (1) estimates the relationship between the results of women's representation and the Gender Inequality Index, which is negative and statistically significant. However, since the index can only reach values between 0 and 1, the interpretation of the estimated coefficients only makes sense if they are divided by 10 . According to model (1), we argue that increasing the GII by 0.1 unit would reduce women's performance by 180.11 FIFA points. This suggests that gender equality has a positive impact on the performance of women's teams, as higher GII values represent higher inequality. A similar result was confirmed in model (2). It is extended by other variables, of which only the indicator of economic prosperity GDPpc - is statistically significant. An economic increase of $1 \%$ has a positive effect on football performance by an average of 118.55 points. The climate and age of footballers are insignificant and therefore do not play a role. Models (3) and (4) estimate the equation for the performance of men's national teams. The results reveal that the effect of increasing gender equality is significantly lower for men, even insignificant in model (4). Age and weather play no role in men's performance either. However, the country's economic prosperity is a major driver of national team performance. Richer countries perform better than poorer ones. GDPpc coefficients are statistically significant for both sexes. 
Table 3. Regression Analysis

\begin{tabular}{|c|c|c|c|c|}
\hline & (1) & (2) & (3) & (4) \\
\hline & Women & Women & Men & Men \\
\hline \multirow[t]{2}{*}{ GII } & $-1,801.102 * * *$ & $-1,141.981 * * *$ & $-899.984 * * *$ & -301.741 \\
\hline & $(312.675)$ & $(311.281)$ & $(213.159)$ & $(338.956)$ \\
\hline \multirow[t]{2}{*}{ GDPpc $(\log )$} & & $118.550 * * *$ & & $97.576 * * *$ \\
\hline & & $(39.777)$ & & $(33.377)$ \\
\hline \multirow[t]{2}{*}{ Temperature } & & -1.990 & & 2.415 \\
\hline & & $(3.960)$ & & $(3.807)$ \\
\hline \multirow[t]{2}{*}{ Age (Female) } & & 603.694 & & \\
\hline & & $(613.429)$ & & \\
\hline \multirow[t]{2}{*}{$\operatorname{Age}^{2}$ (Female) } & & -10.307 & & \\
\hline & & $(12.335)$ & & \\
\hline \multirow[t]{2}{*}{ Age (Male) } & & & & 821.370 \\
\hline & & & & $(1,974.038)$ \\
\hline \multirow[t]{2}{*}{$\operatorname{Age}^{2}$ (Male) } & & & & -15.433 \\
\hline & & & & $(36.878)$ \\
\hline \multirow[t]{2}{*}{ Constant } & $2,021.563 * * *$ & $-7,927.044$ & $1,694.188$ *** & $-10,277.096$ \\
\hline & $(57.284)$ & $(7,448.060)$ & $(38.861)$ & $(26,504.477)$ \\
\hline Observations & 51 & 51 & 51 & 51 \\
\hline R-squared & 0.404 & 0.706 & 0.267 & 0.406 \\
\hline
\end{tabular}

Standard errors in parentheses; Weighted by country population.

$* * * \mathrm{p}<0.01, * * \mathrm{p}<0.05, * \mathrm{p}<0.1$.

One of the subjects of interest is the influence of institutions on the football performance of national teams. Table 4 shows the results of the estimates of equation (2) by gender. The results show that countries that are members of the European Union achieve significantly higher FIFA scores than countries that are not. We attribute this phenomenon to the fact that the free labor market in the European Union allows players from EU countries to move freely between league competitions. For this reason, it is legislatively and bureaucratically easier for players to change their place of action and move to better competition, which further supports the growth of player performance. This effect is higher in women's football than in men's.

In the case of countries that have experienced a communist regime in the past, the presumption prevails that they will achieve lower results than countries in which there was no such regime. The results confirm this hypothesis. We assume that the post-communist countries have lower capital adequacy and thus the infrastructure, whether club or economic, is weaker compared to the countries of the West. This effect is more pronounced in men's football. 
Table 4. Regression Analysis controlling for Institutions

\begin{tabular}{|l|c|c|c|c|c|c|}
\hline & $(\mathbf{1})$ & $\mathbf{( 2 )}$ & $\mathbf{( 3 )}$ & $\mathbf{( 4 )}$ & $\mathbf{( 5 )}$ & $\mathbf{( 6 )}$ \\
\hline & Women & Women & Women & Men & Men & Men \\
\hline EU & $244.762^{* * *}$ & $181.047^{* * *}$ & $325.126^{* * *}$ & $143.542^{* * * *}$ & $86.610^{* * *}$ & $112.984^{* *}$ \\
\hline & $(64.520)$ & $(66.011)$ & $(78.614)$ & $(40.578)$ & $(37.472)$ & $(47.625)$ \\
\hline Post_Communist & & $-171.654^{* *}$ & -12.238 & & $-162.216^{* * *}$ & $-131.952^{* * *}$ \\
\hline & & $(67.019)$ & $(82.693)$ & & $(38.295)$ & $(51.016)$ \\
\hline EU_Communist & & & $-368.331^{* * *}$ & & & -69.686 \\
\hline Constant & & & $(125.695)$ & & & $(77.414)$ \\
\hline & $1,610.520^{* * *}$ & $1,713.804^{* * * *}$ & $1,617.883^{* * *}$ & $1,477.922^{* * *}$ & $1,571.523^{* * *}$ & $1,554.061^{* * * *}$ \\
\hline & $(45.969)$ & $(59.363)$ & $(64.144)$ & $(29.180)$ & $(33.481)$ & $(38.752)$ \\
\hline Observations & & & & & & \\
\hline R-squared & 51 & 51 & 51 & 51 & 51 & 51 \\
\hline S & 0.227 & 0.320 & 0.425 & 0.203 & 0.420 & 0.430 \\
\hline
\end{tabular}

Standard errors in parentheses; Weighted by country population.

*** $\mathrm{p}<0.01, * * \mathrm{p}<0.05, * \mathrm{p}<0.1$

Women's representations in countries that are members of the European Union and have had a communist regime in the past achieve, on average, significantly worse results than their counterparts. In the case of men, this effect has not been confirmed.

\section{Conclusions}

Gender equality has long been considered an important pillar of the development of the nation and democracy. Therefore, it can be concluded that high gender inequality has a negative impact on economic growth as well as the socioeconomic attributes of society. In this paper, we deal with the impact of gender inequality on the performance of men's and women's football teams in an international forum. The results show that higher gender inequality significantly undermines both performances on the pitch for both sexes, which means that countries with higher gender equality perform better in football (H1 - accepted). The economic prosperity of the state, as expected, have a positive statistically significant effect on the results of national teams for both men and women. Countries with higher income levels and better economic as well as sports infrastructure perform better on football pitches (H2 - accepted). Climate and age of athletes, according to our estimates, do not have a significant impact on their performance ( $\mathrm{H} 3$ and $\mathrm{H} 4$ - rejected).

On the contrary, institutional factors related to membership in the European Union have a significantly positive and statistically significant effect on the evaluation of FIFA points (H5 - accepted). This effect is higher in women's game than in men's. Countries in which there was a communist regime in the past achieve an average of 132-172 points less in the FIFA ranking compared to countries that have not experienced this regime, the countries of the West (H6 accepted). This effect is only significant for men. It is interesting to note that women's football teams in countries in the European Union and in which the communist regime was in the past achieve an average of almost 370 points less than their counterparts. In the case of men, this effect is insignificant. 
Policies to improve the situation in the field of gender equality have positive results not only on the economy as such, but also on other areas such as cultural or sports life. Therefore, the society should focus on this area. It is important to keep in mind that women's football can also be an attractive sport.

\section{References}

Berlinschi R, Schokkaert J, Swinnen J (2013) When drains and gains coincide: migration and international football performance. Labour Economics 21(Apr): 1-14.

Cintia P, Giannotti F, Pappalardo L, Pedreschi D, Malvaldi M (2015) The harsh rule of the goals: data-driven performance indicators for football teams. In International Conference on Data Science and Advanced Analytics. IEEE.

Correia A, Esteves S (2007) An exploratory study of spectators' motivation in football. International Journal of Sport Management and Marketing 2(5-6): 572-590.

Hoffmann R, Ging L C, Ramasamy B (2002) The socio-economic determinants of international soccer performance. Journal of Applied Economics 5(2): 253-272.

Hoffmann R, Chew Ging L, Matheson V, Ramasamy B (2006) International women's football and gender inequality. Applied Economics Letters 13(15): 999-1001.

Houston RG, Wilson DP (2002) Income, leisure and proficiency: an economic study of football performance. Applied Economics Letters 9(14): 939-943.

Jacobs JC (2014) Programme-level determinants of women's international football performance. European Sport Management Quarterly 14(5): 521-537.

Leeds MA, Marikova Leeds E (2009) International soccer success and national institutions. Journal of Sports Economics 10(4): 369-390.

Macmillan P, Smith I (2007) Explaining international soccer rankings. Journal of Sports Economics 8(2): 202-213.

Pinnuck M, Potter B (2006) Impact of on-field football success on the off-field financial performance of AFL football clubs. Accounting \& Finance 46(3): 499-517. 